Article

\title{
Cost-Effective Bulk Glass Reinforced Composite Columns
}

\author{
John Cotter ${ }^{(D)}$ and Rasim Guldiken *(D) \\ Department of Mechanical Engineering, University of South Florida, Tampa, FL 33620, USA; \\ Johnmcotter@usf.edu \\ * Correspondence: guldiken@usf.edu; Tel.: +1-813-974-5628
}

Received: 10 April 2020; Accepted: 29 April 2020; Published: 2 May 2020

\begin{abstract}
The cost of construction has been increasing, stemming mostly from increased material costs. One potential method to address this issue is the introduction of novel composites for use in structural applications. Bulk glass may prove to be a superior compositing material due to its low cost and high strength. The introduction of bulk soda-lime glass to structural applications is nontrivial; due to glass' unique properties, such as its relatively low Young's modulus (when compared to steel) and brittleness, compositing glass has proven difficult. A novel concept of a glass-reinforced composite column (GRCC) is introduced that works to benefit from glass' unique properties for structural applications. The results indicate that GRCCs can be designed that have costs that are estimated to be $11 \%$ less than typical timber construction members. Additionally, GRCCs are estimated to provide a $50 \%$ cost advantage over similarly strong structural steel sections. By interpreting the results of finite element modeling, which was conducted iteratively to form buckling load to cost curves, three regions were identified that occur as the glass percentage is increased. These regions also exist with columns made of other materials (such as steel). Additionally, the finite element modeling (FEM)-determined shear stresses have smaller values than the shear strengths of typical sizing agents. In conclusion, GRCCs provide significant cost advantages (up to $50 \%$ cost reduction) over steel, and slight cost advantages when compared to structural timbers, although GRCCs have the added benefit of consisting of non-degrading materials.
\end{abstract}

Keywords: bulk glass reinforcement; glass reinforced composite columns

\section{Introduction}

The concept of bulk glass reinforcement has been introduced for structural systems as a material that can provide lower construction costs when compared against conventional construction materials [1]. The cost advantage occurs due to glass' large compressive strength (1000 MPa [2]; >1100 MPa for fused quartz [3]). When comparing glass directly against other materials, glass can appear more attractive, providing costs that are $20 \%$ that of equivalent strength concrete and $5 \%$ that of equivalent strength steel [1]. However, designing structural elements around the particularities of glass has proven difficult, stemming from glass' relatively low Young's modulus, which is also an issue for pultruded glass fiber reinforced polymers [4].

This paper is in distinction dissimilar to pultruded glass fiber reinforced polymers, such as the focus of studies in References [5-8]. Instead, the glass is presented as a lower-cost bulk cast glass. While pultruded glass fiber composites have their uses, the focus of this paper is instead on composites that can be economically designed when compared against standard construction materials.

This paper assumes that an acceptable bond can be held between the glass and polymers (specifically, high-density polyethylene adhering to soda-lime glass). This could be accomplished by a sizing agent; these chemicals, when applied to glass, allow resins to adhere to them [9]. These are 
commonly utilized in the glass-fiber industry. This is required to allow the polymers to effectively contribute to the buckling resistance of glass by compositing the glass into a matrix with the polymer [10]. Without such agents, the glass will buckle prematurely as the frictional resistance between glass and the supporting polymers will be very low. Special care must be taken when selecting a sizing agent, as it needs to be compatible with the selected polymer. One example would be Michem ${ }^{\circledR}$ Emulsion $93135 \mathrm{M}$, a sizing agent that is polyethylene compatible [11].

One advantage that glass composites may have over competing materials is that the components necessary for glass composites are non-degradable. That is, they do not rot or corrode, unlike reinforced concrete (the reinforcing steel corrodes), steel, or structural timbers. This is similar to the advantages provided by glass fiber-reinforced polymers, which also are non-degradable [12]. Additionally, by securing a cap over both ends of a glass composite, the composite can be completely encased in a polymer. This may provide a competitive edge for glass composites with regard to their use in structures.

The manufacturing process for the glass composite columns (GRCCs) is an extrusion process. More specifically, an over jacketing extrusion process (sometimes called coextrusion, such as in [13], page 683) is considered; in this process, the reinforcing interior of the beam would be fed perpendicularly to the extrusion screw, allowing for the binder to form around the reinforcing core. These manufacturing methods are similar to pultrusion, the method sought by glass fiber-related research (e.g., [5-8]); these manufacturing methods tend to have reduced manufacturing costs [12], leading to more economical designs.

Load and Resistance Factor Design (LRFD) strength reduction factors $(\phi)$ throughout this paper are assumed to be 0.9. However, as concluded by Reference [14], these $\phi$ factors may need to be reduced in certain circumstances, as they would need to be for the similar pultruded glass fiber-reinforced polymers. Therefore, the strengths referenced in this paper are listed as the maximum strength of the section $(P n)$.

This paper investigates the possibility of GRCCs providing a cost-competitive alternative to other construction materials. Sections 2 and 3 investigate a $2 \times 4$ stud (nominally 2 inches by 4 inches lumber planed down to 1.5 inches by 3.5 inches, or nominally $51 \mathrm{~mm}$ by $102 \mathrm{~mm}$ planed down to $38 \mathrm{~mm}$ by $89 \mathrm{~mm}$ ) replacement and Sections 4 and 5 investigate the cost comparison between a series of hollow-structural-steel (HSS) section equivalents using GRCCs.

The targeted applications of GRCCs are the replacement of standard construction columns as well as applications where inert construction materials are preferred or required, such as chemical plants processing corrosive materials, power poles, and salt-water applications.

Composite $2 \times 4$ studs have been conceptualized and patented previously, such as in Reference [15]. The composite studs characterized in this patent, however, did not seek to reduce costs but to increase the functionality of steel studs by compositing them with other materials. Through the finite element modeling (FEM) conducted as part of this paper, and using the cost assumptions presented, GRCCs is a cost competitive material when compared against both structural timbers and structural steel.

\section{Analytical Design for $2 \times 4$ Douglas Fir Equivalent}

To create a GRCC of similar buckling load as the buckling load of a $2 \times 4(38 \mathrm{~mm} \times 89 \mathrm{~mm})$ stud, it is necessary to clearly identify the buckling load and cost of the competing material. Due to the cyclical nature of the timber market, cost comparisons can be difficult. For the purposes of this paper, a price of USD 525 per MBF (thousand board feet), which is equivalent to USD $222.5 / \mathrm{m}^{3}$, is assumed; this represents the price of kiln dried Douglas fir timber as of March 2020 [16]. Therefore, the selected column length of $2440 \mathrm{~mm}$ ( 8 feet) results in a cost of USD 1.835 (USD) for a Douglas fir stud. This value is an intermediate price for timber; as Reference [17] indicated, the recent high for Douglas fir was USD 690 in June 2018, which would be a price of USD 2.411 per stud.

As this section suggests, the goal is the analytical design of a $2 \times 4$ Douglas fir equivalent. For purposes of comparison, both weak and strong axis bending will be compared. Accordingly, 
the buckling loads of Douglas fir timber is summarized in Table 1. This table compares the buckling loads of No. 3-1 and select structural lumber. Note that this table assumes a variety of Young's moduli ranging from 510,000 (3.54 GPa) to 690,000 psi (4.79 GPa), which varies with the grade of the lumber. The source for these buckling load values is Reference [18], which utilized the design requirements put forth by Reference $[19,20]$.

Table 1. The buckling loads of various timber grades of Douglas fir.

\begin{tabular}{ccccc}
\hline Grade & Weak Axis (lbs) & Weak Axis (kN) & Strong Axis (lbs) & Strong Axis (kN) \\
\hline Select Structural & 716 & 3.18 & 3576 & 15.91 \\
\hline No. 1 & 643 & 2.86 & 3205 & 14.26 \\
\hline No. 2 & 601 & 2.67 & 2983 & 13.27 \\
\hline No. 3 & 524 & 2.33 & 2412 & 10.73 \\
\hline
\end{tabular}

Now, considering the glass columns, it should first be mentioned how the GRCCs are assumed to be constructed. An example of the composite prior to over jacket extrusion is shown in Figure 1. In this figure, two glass plates are supported by an inner sleeve, which is a simplistic extruded high-density polyethylene (HDPE) shape. This is necessary to prevent the glass plates from pressing together during the over jacket extrusion process.

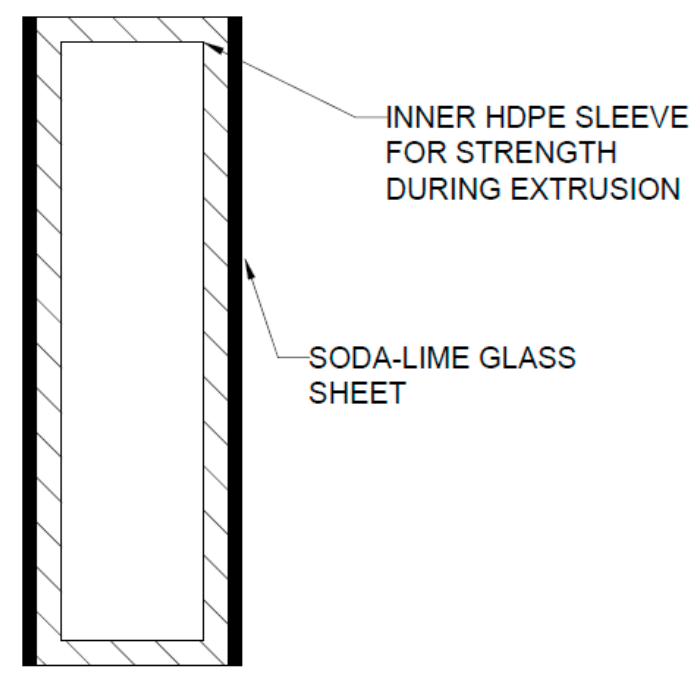

Figure 1. The glass-reinforced composite column (GRCC) is first assembled using an inner sleeve to hold the glass in place during the over jacketing extrusion process.

For buckling analysis, it is considered that the glass plates will not slide relative to the outside sleeve of HDPE. That is, the glass plates are assumed to be bonded to the exterior HDPE sleeve. To prove this condition, additional physical testing is necessary to be conducted. However, as Section 7 . Required Bond Strengths indicates, the bonding strength necessary can likely be met with a sizing agent. These sizing agents work to bond glass to polymers, of which there exists sizing agents specifically developed to allow HDPE to stick to soda-lime glass.

For an explanation on the specific contact conditions, see Figure 2. The interior sleeve is considered to be unbonded to the glass plates for this analysis, and the coefficient of friction between this interior sleeve and glass plates is assumed sufficiently. The interior sleeve does serve two purposes; it provides support to the GRCC during the over jacket extrusion process, and it increases the material thickness that fasteners would be attached to. 


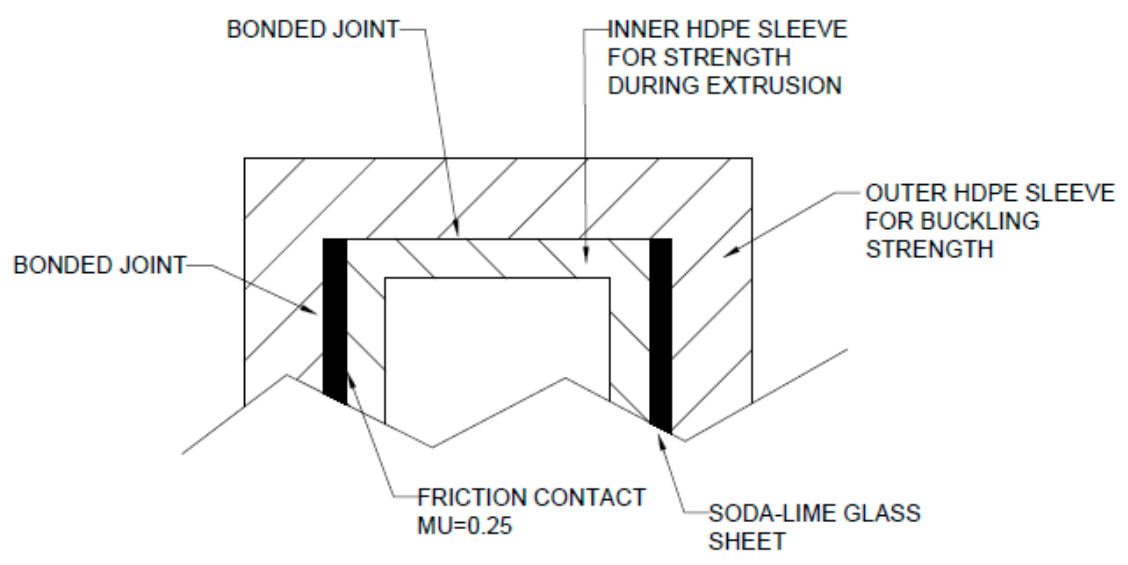

Figure 2. The bonding conditions between the inner sleeve, outer sleeve, and soda-lime glass plates is shown.

To limit the analytical analysis, a single arrangement for the GRCC will be considered. The considered dimensions are $6 \mathrm{~mm}$ for the exterior thickness, $3 \mathrm{~mm}$ for the interior thickness, and a glass sheet thickness of $1.6 \mathrm{~mm}$ (equivalent to $1 / 16$ inches). This specific arrangement is shown in Figure 3. Note that this design provides $9 \mathrm{~mm}$ thickness of HDPE for securing anchors to the GRCC $2 \times 4$ equivalent.

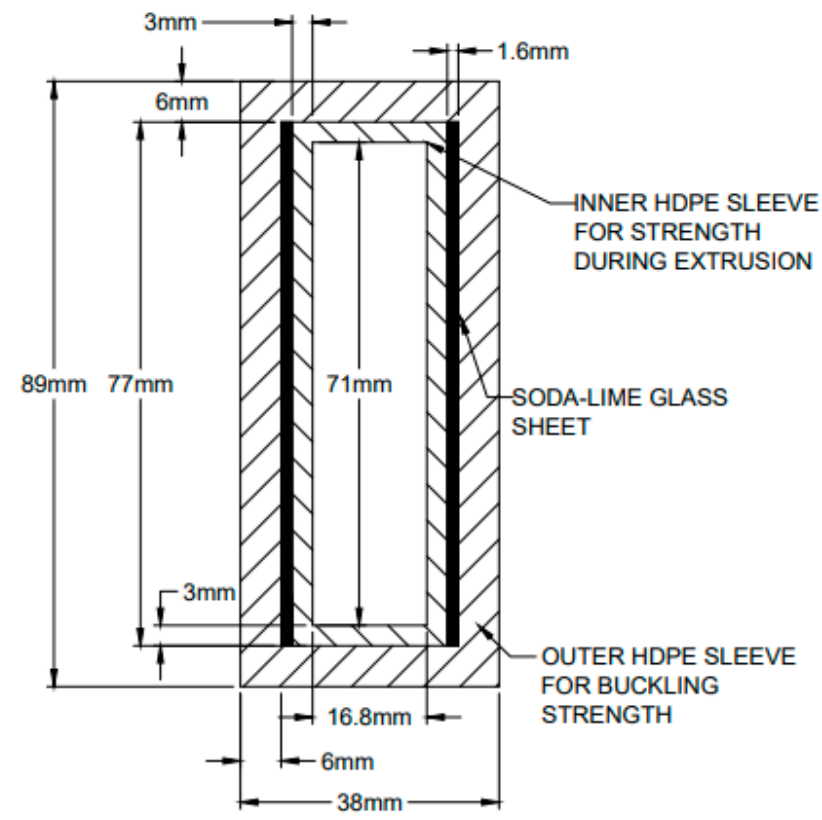

Figure 3. A cross-section of the analytically designed $2 \times 4$ GRCC equivalent.

As the section behaves as a complete unit, the moments of inertia necessary to calculate the buckling load can be determined by simply considering the glass' contributions. This is appropriate as the Young's modulus of glass is 72 GPa [21], while the Young's modulus of HDPE is only 0.8 GPa [22]; this means the HDPE contributes little to the buckling load of the column.

The resulting calculations are included in the Appendix A, Equations (A1)-(A7). This results in a GRCC with a weak axis buckling load of $4768 \mathrm{~N}$ and a strong axis buckling load of 16,163 N.

As can be seen, if the glass is allowed to function as a column, and not to suffer from a local buckling condition, the glass deforms as a section, resulting in significant buckling load. In fact, the 
calculated buckling load of the GRCC for the analytical section is equivalent in buckling load to a No. 1 Douglas fir $2 \times 4$.

Now, the costs are estimated. Considering a soda-lime glass price of USD 0.17 per kg [23], and an HDPE cost of USD 0.25 per $\mathrm{kg}$ [24], the resulting estimated cost is USD 2.31. This estimated cost includes a factor of $40 \%$ of the cost for the manufacturing cost of the extrusion, as suggested by [25]. As over jacket extrusion is assumed for manufacturing GRCCs, but is not explicitly detailed in [25], the specific cost factoring may be inaccurate, but is considered as an approximation of the true cost of GRCCs. This is at a cost disadvantage to Douglas fir timber (\$1.835), costing 26\% more. However, as the timber market is cyclical, prices for Douglas fir have climbed as high as \$2.411 (USD) per 8-foot $2 \times 4$. Due to GRCCs non-degradability, the premium pricing may provide marketability for GRCCs.

While this first analytical design is at a cost disadvantage, other designed GRCCs have costs approaching or below the price of timber, as is developed and described in the following section on finite element modeling (FEM) of GRCCs.

\section{Finite Element Modeling for $2 \times 4$ Douglas Fir Equivalent}

To extrapolate on the solution calculated previously, finite element modeling (FEM) is conducted. In particular, the program utilized is ANSYS 2019 R3, utilizing the Static Structural and Eigenvalue Buckling Analysis Systems. The specific reason that buckling is considered extensively is that the maximum glass stress encountered in all of the analyses is $123 \mathrm{MPa}$ (which is derived from $73.9 \mathrm{MPa}$ multiplied by a safety factor conversion of 1.67), a value that is $12.3 \%$ the maximum strength value for glass (glass has a strength of $1000 \mathrm{MPa}$ in compression, [2]). This means that the columns considered as part of this research are limited by the buckling strength and not the compressive strength of glass.

The general design for the $2 \times 4$ equivalent GRCCs is shown in Figure 4. In this figure, the thickness of the exterior (denoted ES THICKNESS) and interior (denoted IS THICKNESS) HDPE sleeves will be modulated, and the glass thicknesses (denoted GP THICKNESS) will be varied in the design.

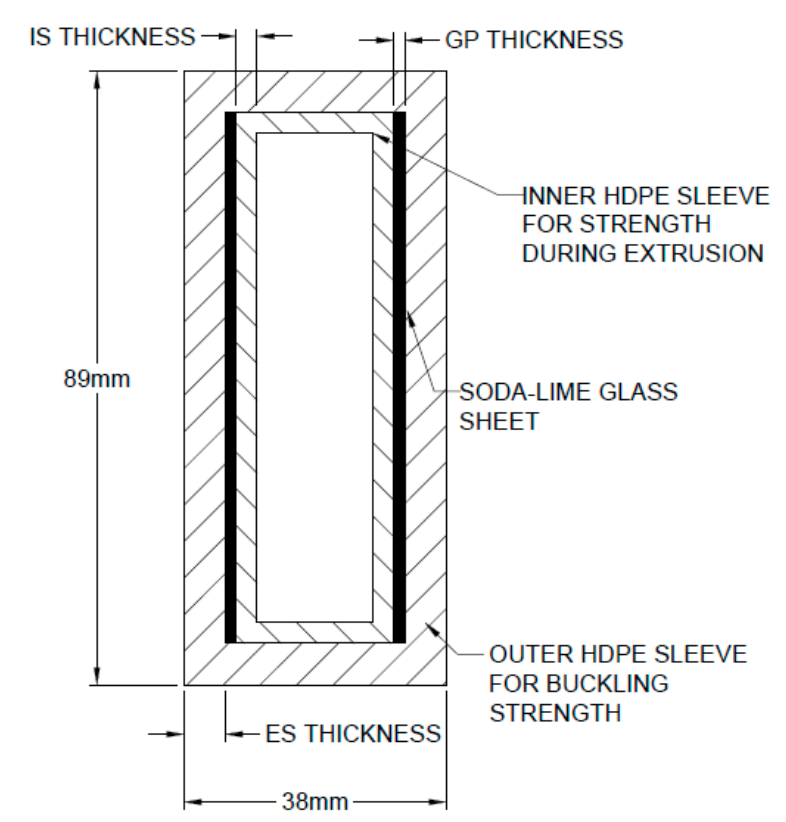

Figure 4. The general shape for the $2 \times 4$ replacement columns.

An example of the cross-section is shown in Figure 5. One additional note is that the length of the analyzed members was reduced to $\frac{1}{2}$ the selected length; this was done as the ANSYS analysis was performed as a fixed-free buckling condition; this means that the value of $k L$ (the effective buckling length of a column) between the two analyses (between the analytical analysis required to determine the 
buckling loads of the timber columns and the ANSYS FEM) was equivalent (that is, $k L=1.0 \times 2.44 \mathrm{~m}$ $=2.0 \times 1.22 \mathrm{~m}=2.44 \mathrm{~m}$ ).

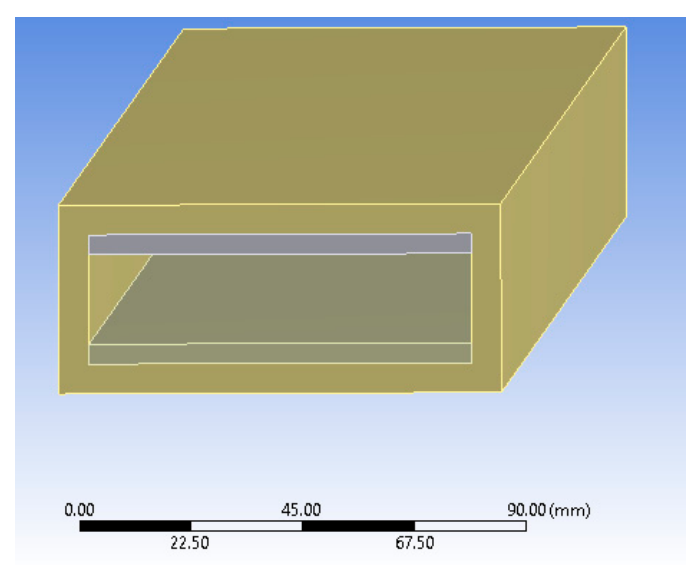

Figure 5. The cross section of one of the analyzed columns (placed on its side).

Next, the results of the iterative analysis are shown in Table 2. In this table, the section designation is organized such that the two numbers represent the outside dimensions of the section (a standard $89 \mathrm{~mm}$ by $38 \mathrm{~mm}$ ), the third number represents the exterior sleeve thickness (ES THICKNESS in Figure 4), and the fourth number represents the glass plate thickness (GP THICKNESS in Figure 4). A standard interior sleeve thickness of $3 \mathrm{~mm}$ was assumed.

Table 2. The resulting weak and strong axis buckling loads of the GRCCs targeting a substitution for standard $2 \times 4$ stud timber framing.

\begin{tabular}{|c|c|c|c|c|c|}
\hline Section & $\begin{array}{l}\text { Analysis } \\
\text { Mesh Size }\end{array}$ & $\begin{array}{l}\text { Weak Axis Critical } \\
\text { Buckling Load (kN) }\end{array}$ & $\begin{array}{l}\text { Strong Axis Critical } \\
\text { Buckling Load (kN) }\end{array}$ & $\begin{array}{l}\text { Maximum Glass } \\
\text { Stress (MPa) }\end{array}$ & $\begin{array}{l}\text { Estimated Cost } \\
\text { (\$USD) }\end{array}$ \\
\hline $89 \times 38 \times 3 \times 1$ & $12.5 \mathrm{~mm}$ & 4.4 & 12.3 & 73.9 & $\$ 1.63$ \\
\hline $89 \times 38 \times 3 \times 1.6$ & $12.5 \mathrm{~mm}$ & 6.4 & 19.0 & 71.4 & $\$ 1.80$ \\
\hline $89 \times 38 \times 3 \times 2$ & $12.5 \mathrm{~mm}$ & 7.5 & 23.3 & 70.1 & $\$ 1.92$ \\
\hline $89 \times 38 \times 3 \times 3$ & $12.5 \mathrm{~mm}$ & 10.3 & 35.0 & 70.3 & $\$ 2.20$ \\
\hline $89 \times 38 \times 3 \times 4$ & $12.5 \mathrm{~mm}$ & 12.0 & 37.2 & 56.0 & $\$ 2.49$ \\
\hline $89 \times 38 \times 6 \times 1$ & $12.5 \mathrm{~mm}$ & 3.1 & 10.7 & 69.7 & $\$ 2.15$ \\
\hline $89 \times 38 \times 6 \times 1.6$ & $12.5 \mathrm{~mm}$ & 4.5 & 16.2 & 65.7 & $\$ 2.31$ \\
\hline $89 \times 38 \times 6 \times 2$ & $12.5 \mathrm{~mm}$ & 5.3 & 19.8 & 64.3 & $\$ 2.41$ \\
\hline $89 \times 38 \times 6 \times 3$ & $12.5 \mathrm{~mm}$ & 7.0 & 28.9 & 62.5 & $\$ 2.68$ \\
\hline $89 \times 38 \times 6 \times 4$ & $12.5 \mathrm{~mm}$ & 8.4 & 38.0 & 61.6 & $\$ 2.95$ \\
\hline $89 \times 38 \times 9 \times 1$ & $12.5 \mathrm{~mm}$ & 2.0 & 9.3 & 65.6 & $\$ 2.62$ \\
\hline $89 \times 38 \times 9 \times 1.6$ & $12.5 \mathrm{~mm}$ & 2.7 & 13.6 & 59.8 & $\$ 2.77$ \\
\hline $89 \times 38 \times 9 \times 2$ & $12.5 \mathrm{~mm}$ & 3.1 & 16.4 & 57.8 & $\$ 2.86$ \\
\hline $89 \times 38 \times 9 \times 3$ & $12.5 \mathrm{~mm}$ & 4.0 & 23.5 & 55.3 & $\$ 3.11$ \\
\hline $89 \times 38 \times 9 \times 4$ & $12.5 \mathrm{~mm}$ & 4.6 & 28.9 & 50.9 & $\$ 3.36$ \\
\hline
\end{tabular}

The resulting analysis found two modes of failure among all dimensions shown in Table 2. The failure modes were gross deflection of the weak and strong axes. These can be seen in Figures 6 and 7 . 
Note that the buckling modes were gross-buckling of the GRCCs. This is in distinction to local buckling failures, which were seen in the hollow-structural-steel GRCC replacements.

To better understand the findings of the FEM, graphs were developed. The data between the timber section buckling loads, timber costs, and estimated costs and buckling loads of the GRCC equivalents were collated into two figures. Figure 8 shows the weak axis buckling load vs. cost, while Figure 9 shows the same for the strong axis buckling. Note that the timber buckling loads are graphed as horizontal lines while the timber costs are vertical lines.

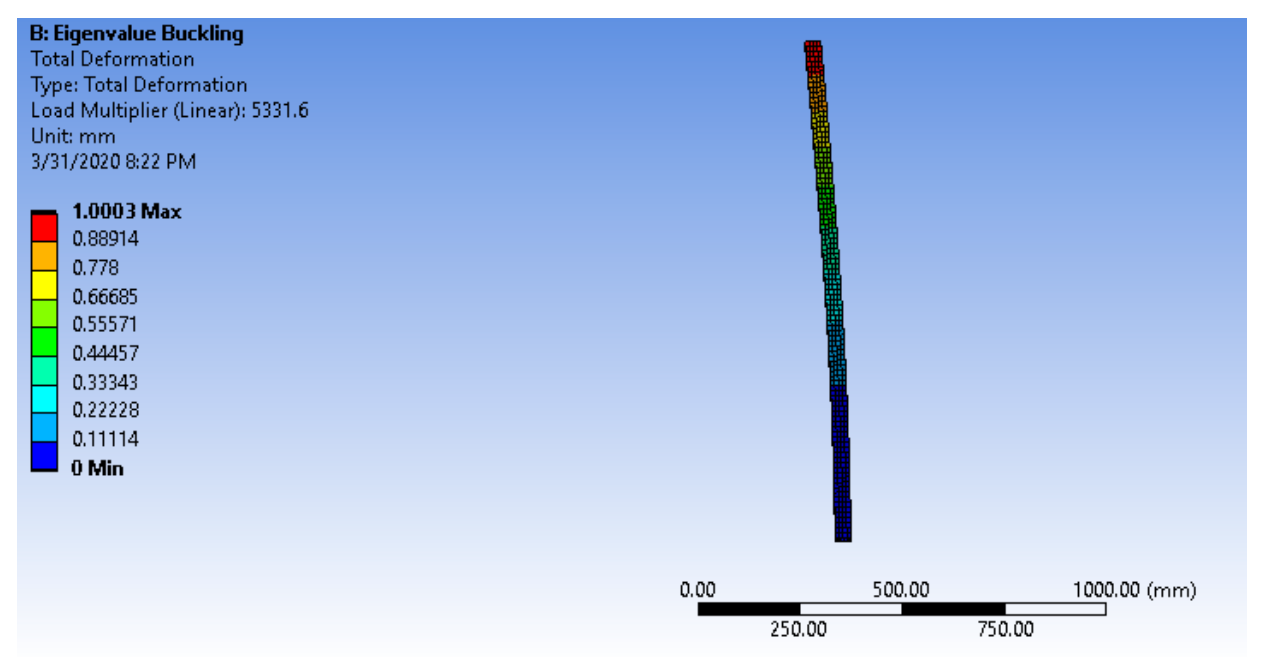

Figure 6. The first mode of buckling failure was the gross-buckling of the GRCC along the weak axis.

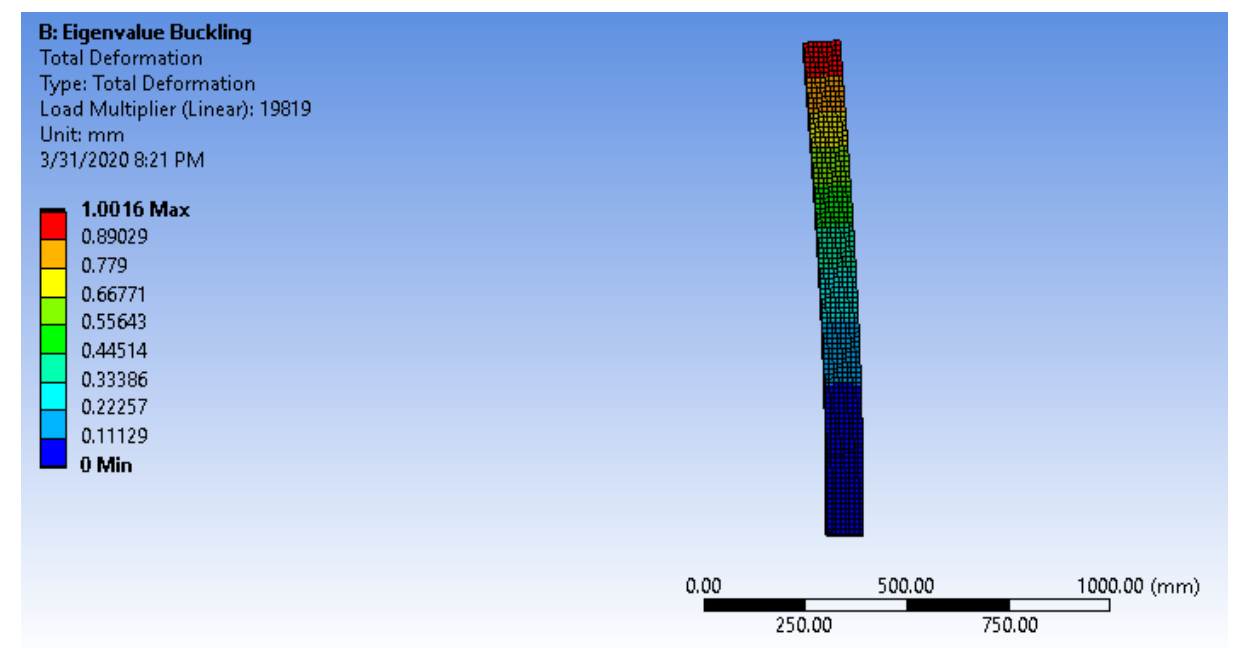

Figure 7. The second mode of buckling failure was gross-buckling along the strong axis.

As can be seen in Figures 8 and 9, the most cost-effective sizes are $89 \times 38 \times 3$ GRCCs. These can approach a price of USD 1.63 if utilizing a $1 \mathrm{~mm}$ glass plate thickness, which results in a cost saving of $11 \%$ over current timber prices (USD 1.835). This section, however, only beats the buckling load of No. 3 grade timber, so the glass plate thickness would need to be modulated until an acceptable design was found.

The $89 \times 38 \times 3$ GRCCs feature a $3 \mathrm{~mm}$ exterior sleeve, which is more problematic with respect to utility. The polymer sheeting allows for fasteners to attach to the GRCC. The total thickness of the $89 \times 39 \times 3$ GRCCs is $6 \mathrm{~mm}$ ( $3 \mathrm{~mm}$ from the exterior, $3 \mathrm{~mm}$ from the interior sleeve). This may be an unacceptably thin region for practical purposes. 


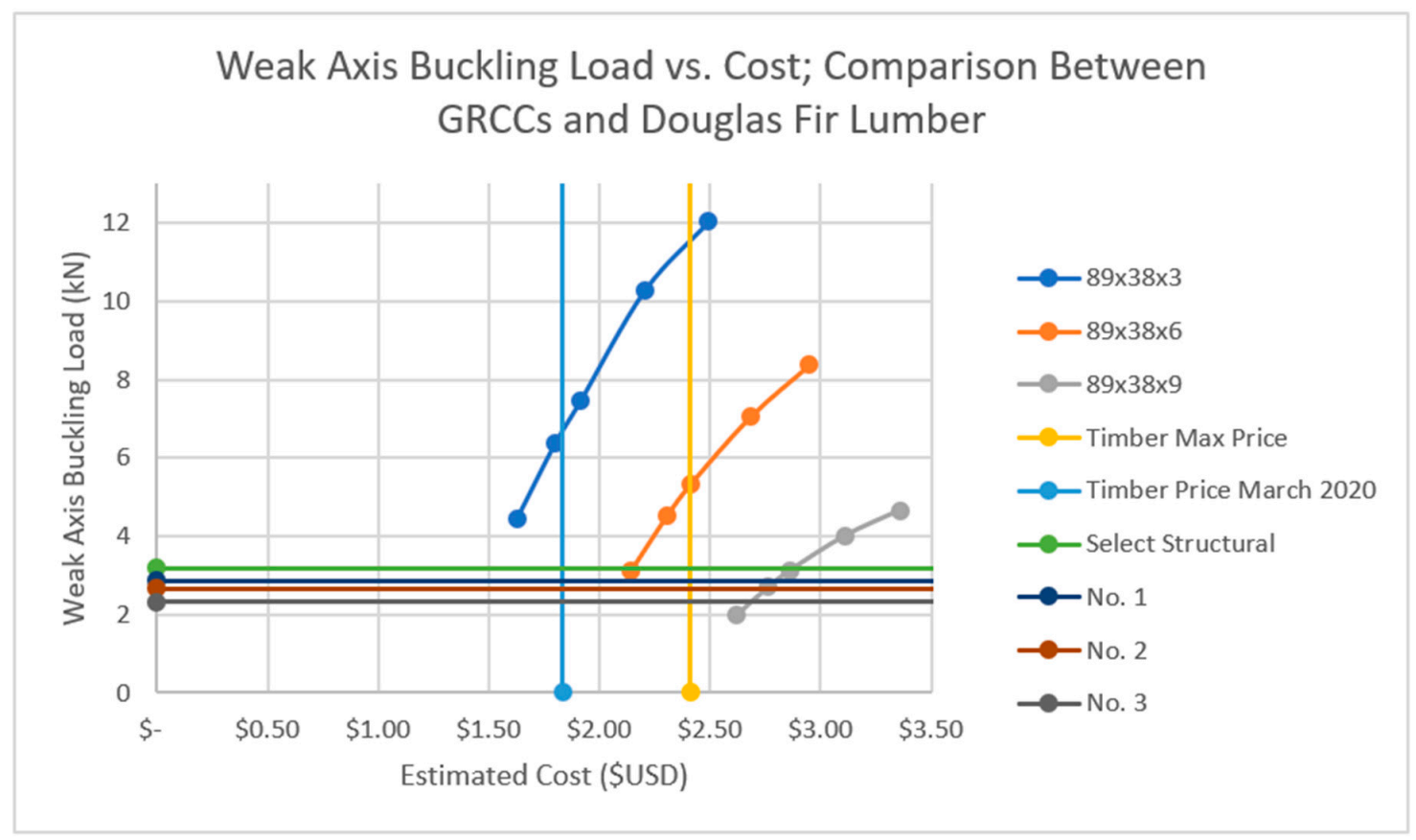

Figure 8. The cost vs. buckling load comparison for the weak axis buckling comparison.

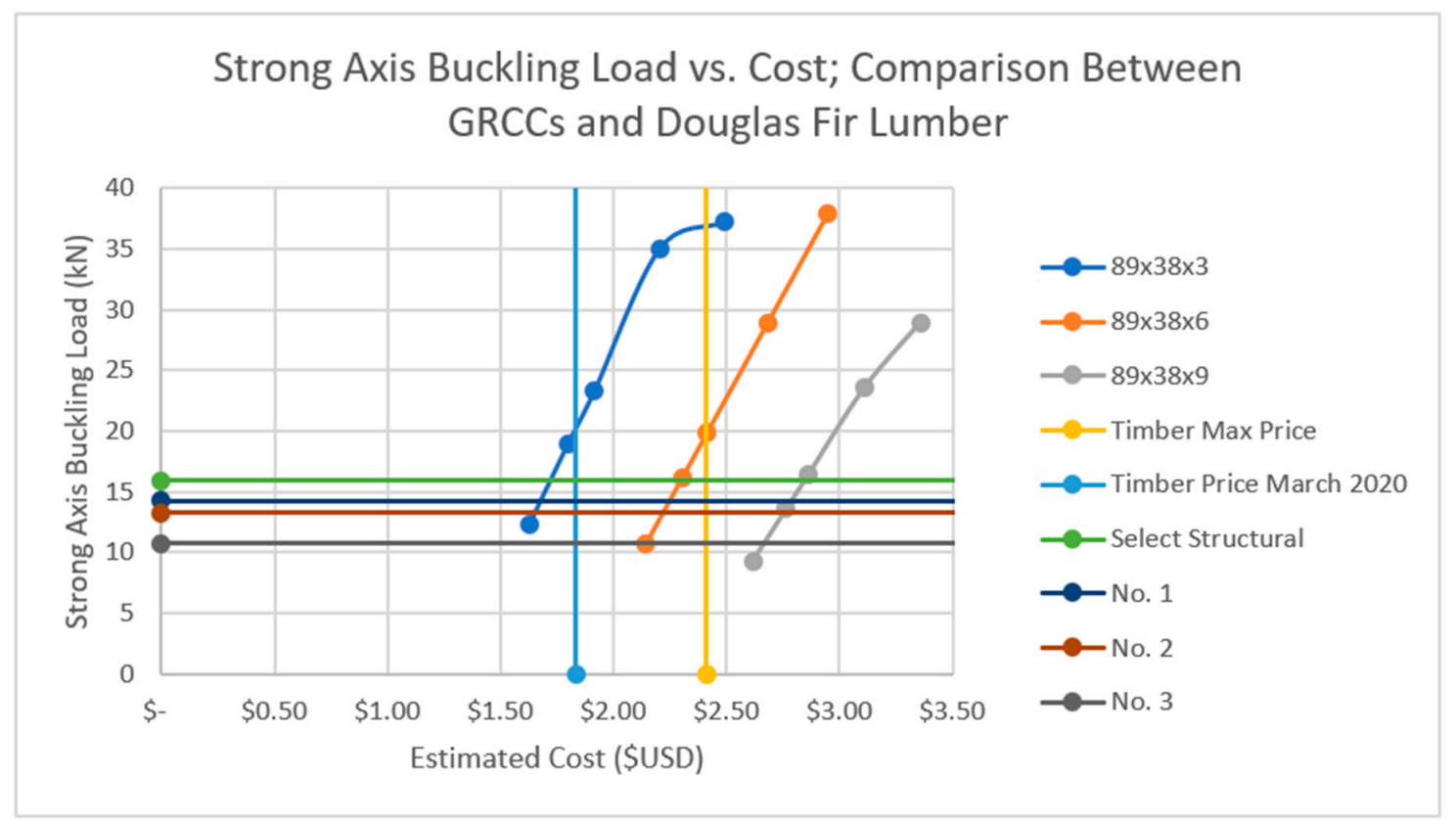

Figure 9. The cost vs. strong axis buckling load comparison for the various grades of Douglas fir and the GRCC equivalents.

\section{Analytical Design for $5 \times 5 \times 1 / 8$ Steel Equivalent}

As it would be insufficient to only calculate and compare buckling loads of GRCCs against timber structural members, a similar comparison analysis will also be performed for a GRCC that matches the requirements of buckling load as an HSS $5 \times 5 \times 1 / 8$ (the metric equivalent being HSS $127 \times 127 \times 3.2$ ). For this shape, the maximum load (assuming LRFD design) is $355 \mathrm{kN}$ (note that this is the value of $P_{n}$, the nominal buckling load without the 0.9 reduction factor). For this shape, an equivalent GRCC is designed. 
The selected GRCC is a $125 \mathrm{~mm} \times 125 \mathrm{~mm}$ section with $12.5 \mathrm{~mm}$ thickness glass sheets. A standard sleeve thickness of $3 \mathrm{~mm}$ is assumed for both the interior and exterior HDPE sleeves. An example of the selected member is shown in Figure 10. Note that the design features four glass plates of varying widths, unlike the two glass plates utilized for the equivalent stud GRCC.

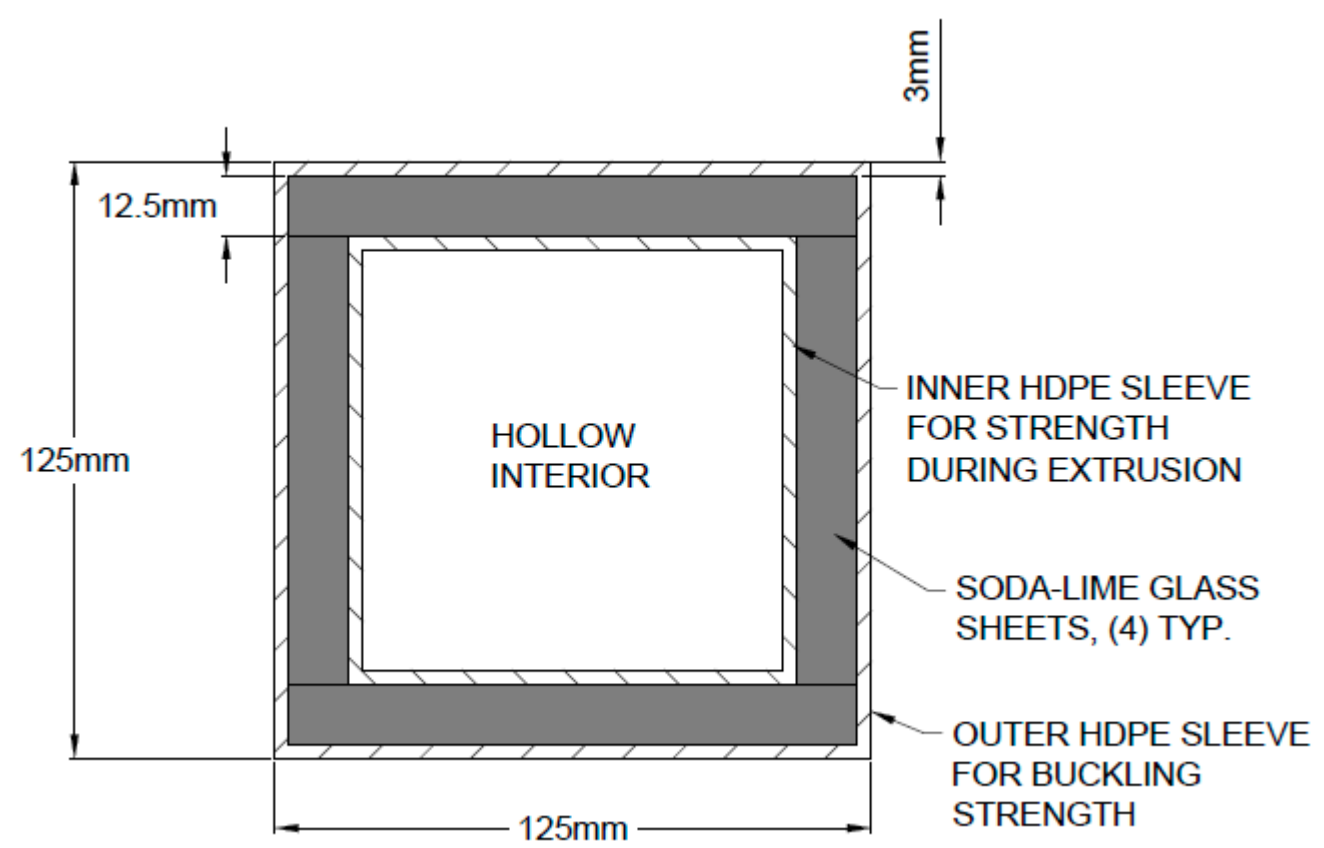

Figure 10. The cross-section of the selected GRCC for equivalent buckling load as an HSS $5 \times 5 \times 1 / 8$.

As with the previous GRCCs, it is absolutely necessary for the HDPE sleeve to bond to the glass sheet.

First, the costs of the steel need to be presented. Based on a current steel price of USD 0.77per $\mathrm{kg}$ [26], and assuming A36 plate prices are equivalent to A500 grade B (which is what hollow structural steel sections are typically composed of), the resulting prices for the selected sections for comparison are shown in Table 3.

The selected design for comparison is an HSS $127 \times 127 \times 3.2($ HSS $5 \times 5 \times 1 / 8)$. For this section, the unreduced buckling load is $355.36 \mathrm{kN}$.

Now, the equivalent buckling load GRCC is designed. The selected GRCC is a $125 \mathrm{~mm} \times 125$ mm section with $12.5 \mathrm{~mm}$ thickness glass sheets and an HDPE sleeve of $3 \mathrm{~mm}$ (which is designated a $125 \times 125 \times 3 \times 12.5$ ). As before, the section is assumed to deform as a solid component. This results in the glass not locally buckling but deforming the entire column as a complete unit. For the purposes of the analytical design, the frictional contact between the glass plates will not be considered for analysis.

The resulting calculations are included in the Appendix A, Equations (A8) and (A9). This results in a GRCC with a $669 \mathrm{kN}$.

However, due to the complex interaction between the glass plates, this critical load calculated analytically is proven to be incorrect in the finite element section. That being said, the FEM-determined buckling load surpasses the HSS buckling load of $355.36 \mathrm{kN}$. An explanation for the difference in buckling load is presented in the following section.

Additionally, using the same cost assumptions as before, the cost of the GRCC $125 \mathrm{~mm} \times 125 \mathrm{~mm}$ with $12.5 \mathrm{~mm}$ glass plates is USD 15.12; this is significantly lower than the HSS $127 \times 127 \times 3.2$ (HSS 5 $\times 5 \times 1 / 8)$ at a cost of USD 26.42. This would be a cost saving of $43 \%$ over the equivalent steel section. 
Table 3. The costs assumed for the steel sections. This is based on a current (as of 1 April 2020) price of steel plate of USD 0.77 per $\mathrm{kg}$. The assumed column length is $3050 \mathrm{~mm}$ (10 feet).

\begin{tabular}{|c|c|c|c|}
\hline \multicolumn{4}{|c|}{ Steel Sections } \\
\hline Section (Standard Designation) & Section (Metric Designation) & $\operatorname{Pn}(\mathbf{k N})$ & Estimated Cost (\$USD) \\
\hline HSS $2 \times 2 \times 1 / 8$ & HSS $50.8 \times 50.8 \times 3.2$ & 37.71 & $\$ 9.92$ \\
\hline HSS $2 \times 2 \times 3 / 16$ & HSS $50.8 \times 50.8 \times 4.8$ & 49.92 & $\$ 14.05$ \\
\hline HSS $2 \times 2 \times 1 / 4$ & HSS $50.8 \times 50.8 \times 6.4$ & 57.83 & $\$ 17.83$ \\
\hline HSS $2.25 \times 2.25 \times 1 / 8$ & HSS $57.2 \times 57.2 \times 3.2$ & 55.36 & $\$ 11.29$ \\
\hline HSS $2.25 \times 2.25 \times 3 / 16$ & HSS $57.2 \times 57.2 \times 4.8$ & 74.14 & $\$ 16.18$ \\
\hline HSS $2.25 \times 2.25 \times 1 / 4$ & HSS $57.2 \times 57.2 \times 6.4$ & 87.48 & $\$ 20.56$ \\
\hline HSS $2.5 \times 2.5 \times 1 / 8$ & HSS $63.5 \times 63.5 \times 3.2$ & 77.60 & $\$ 12.64$ \\
\hline HSS $2.5 \times 2.5 \times 3 / 16$ & HSS $63.5 \times 63.5 \times 4.8$ & 104.78 & $\$ 18.20$ \\
\hline HSS $2.5 \times 2.5 \times 1 / 4$ & HSS $63.5 \times 63.5 \times 6.4$ & 126.03 & $\$ 23.28$ \\
\hline HSS $2.5 \times 2.5 \times 5 / 16$ & HSS $63.5 \times 63.5 \times 7.9$ & 141.35 & $\$ 27.78$ \\
\hline HSS $3 \times 3 \times 1 / 8$ & HSS $76.2 \times 76.2 \times 3.2$ & 131.47 & $\$ 15.37$ \\
\hline HSS $3 \times 3 \times 3 / 16$ & HSS $76.2 \times 76.2 \times 4.8$ & 183.86 & $\$ 22.35$ \\
\hline HSS $3 \times 3 \times 1 / 4$ & HSS $76.2 \times 76.2 \times 6.4$ & 228.34 & $\$ 28.85$ \\
\hline HSS $3 \times 3 \times 5 / 16$ & HSS $76.2 \times 76.2 \times 7.9$ & 263.43 & $\$ 34.77$ \\
\hline HSS $3 \times 3 \times 3 / 8$ & HSS $76.2 \times 76.2 \times 9.5$ & 291.11 & $\$ 40.10$ \\
\hline HSS $3.5 \times 3.5 \times 1 / 8$ & HSS $88.9 \times 88.9 \times 3.2$ & 187.81 & $\$ 18.22$ \\
\hline HSS $3.5 \times 3.5 \times 3 / 16$ & HSS $88.9 \times 88.9 \times 4.8$ & 267.88 & $\$ 26.50$ \\
\hline HSS $3.5 \times 3.5 \times 1 / 4$ & HSS $88.9 \times 88.9 \times 6.4$ & 340.04 & $\$ 34.43$ \\
\hline HSS $3.5 \times 3.5 \times 5 / 16$ & HSS $88.9 \times 88.9 \times 7.9$ & 401.82 & $\$ 41.66$ \\
\hline HSS $3.5 \times 3.5 \times 3 / 8$ & HSS $88.9 \times 88.9 \times 9.5$ & 454.21 & $\$ 48.41$ \\
\hline HSS $4 \times 4 \times 1 / 8$ & HSS $101.6 \times 101.6 \times 3.2$ & 245.15 & $\$ 20.95$ \\
\hline HSS $4 \times 4 \times 3 / 16$ & HSS $101.6 \times 101.6 \times 4.8$ & 353.38 & $\$ 30.55$ \\
\hline HSS $4 \times 4 \times 1 / 4$ & HSS $101.6 \times 101.6 \times 6.4$ & 453.72 & $\$ 39.90$ \\
\hline HSS $4 \times 4 \times 5 / 16$ & HSS $101.6 \times 101.6 \times 7.9$ & 543.67 & $\$ 48.55$ \\
\hline HSS $4 \times 4 \times 3 / 8$ & HSS $101.6 \times 101.6 \times 9.5$ & 622.75 & $\$ 56.61$ \\
\hline HSS $4 \times 4 \times 1 / 2$ & HSS $101.6 \times 101.6 \times 12.7$ & 756.19 & $\$ 71.31$ \\
\hline HSS $5 \times 5 \times 1 / 8$ & HSS $127 \times 127 \times 3.2$ & 355.36 & $\$ 26.42$ \\
\hline HSS $5 \times 5 \times 3 / 16$ & HSS $127 \times 127 \times 4.8$ & 523.90 & $\$ 38.86$ \\
\hline HSS $5 \times 5 \times 1 / 4$ & HSS $127 \times 127 \times 6.4$ & 677.11 & $\$ 50.95$ \\
\hline HSS $5 \times 5 \times 5 / 16$ & HSS $127 \times 127 \times 7.9$ & 825.39 & $\$ 62.34$ \\
\hline HSS $5 \times 5 \times 3 / 8$ & HSS $127 \times 127 \times 9.5$ & 958.83 & $\$ 73.25$ \\
\hline HSS $5 \times 5 \times 1 / 2$ & HSS $127 \times 127 \times 12.7$ & 1201.01 & $\$ 93.41$ \\
\hline HSS $6 \times 6 \times 1 / 8$ & HSS $152.4 \times 152.4 \times 3.2$ & 403.30 & $\$ 32.01$ \\
\hline HSS $6 \times 6 \times 3 / 16$ & HSS $152.4 \times 152.4 \times 4.8$ & 682.06 & $\$ 47.19$ \\
\hline HSS $6 \times 6 \times 1 / 4$ & HSS $152.4 \times 152.4 \times 6.4$ & 899.53 & $\$ 62.14$ \\
\hline HSS $6 \times 6 \times 5 / 16$ & HSS $152.4 \times 152.4 \times 7.9$ & 1097.22 & $\$ 76.26$ \\
\hline HSS $6 \times 6 \times 3 / 8$ & HSS $152.4 \times 152.4 \times 9.5$ & 1285.04 & $\$ 89.91$ \\
\hline HSS $6 \times 6 \times 1 / 2$ & HSS $152.4 \times 152.4 \times 12.7$ & 1640.89 & $\$ 115.55$ \\
\hline HSS $6 \times 6 \times 5 / 8$ & HSS $152.4 \times 152.4 \times 15.9$ & 1952.27 & $\$ 138.82$ \\
\hline
\end{tabular}

\section{Finite Element Modeling for $5 \times 5 \times 1 / 8$ Steel Equivalent}

As before, FEM was conducted of iterative designs to showcase the variety of buckling loads and costs possible for GRCCs. FEM was conducted using ANSYS 2019 R3's Static Structural and Eigenvalue 
Buckling Analysis Systems. Before displaying the FEM determined results, it is necessary to describe the standardized shape. Figure 11 below shows the shape that was modulated. As before, there are four primary measurements; the outside dimensions (denoted OD), the exterior sleeve thickness (denoted ES THICKNESS), the glass plate thickness (denoted GP THICKNESS), and the interior sleeve thickness (denoted IS THICKNESS).

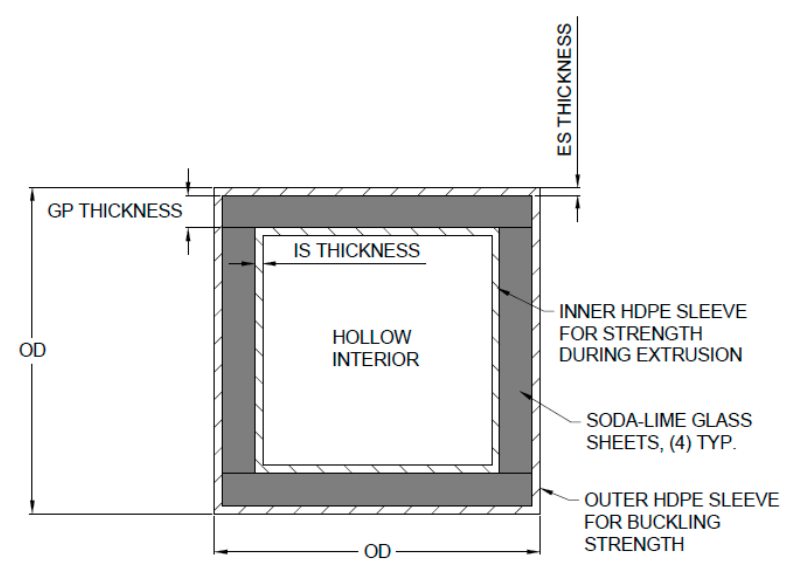

Figure 11. The general arrangement of the GRCC that works as a replacement for HSS columns.

An explanation of the contact conditions for the GRCCs analyzed using FEM are presented in Figure 12. The inner contact with a frictional coefficient of 0.25 (the author's estimate) is not reflected in the FEM as the inner sleeves were excluded from the analysis (as they contribute a negligible amount of buckling load). The glass plates have a coefficient of friction of 0.95 [27] between them.

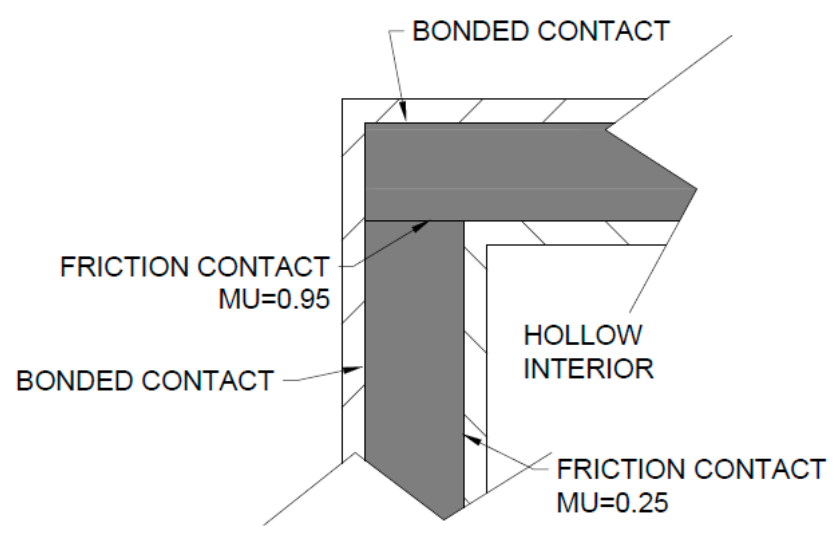

Figure 12. The contact conditions are shown on the upper-left portion of Figure 11, for the various components of the GRCCs considered.

Next, the results of the FEM are listed in Table 4. In this table, the mesh size, maximum buckling load, maximum glass stress, and estimated cost are listed. Note that while two modes of buckling were calculated, only the first mode is reported.

This table presents an issue with the analytically determined buckling load of the $125 \times 125 \times$ $3 \times 12.5$; the analytical buckling load was calculated as $669 \mathrm{kN}$ and the FEM resulted in a buckling load of $425 \mathrm{kN}$. The difference between these two values is thought to derive from the inclusion of the frictional joint between the glass plates (as shown in Figure 12). This frictional joint, which is intrinsically assumed as bonded in the analytical section, significantly reduces the buckling load of the section. As the FEM can account for this interaction while the analytical does not, the results from the FEM are considered more accurate. 
Table 4. The mesh sizes, buckling loads, maximum glass stresses, and estimated costs are presented for the finite element modeling (FEM) GRCCs. Note that the designation is OD $\times \mathrm{OD} \times \mathrm{ES} \times \mathrm{GP}$ (see Figure 11 for references to the dimensions).

\begin{tabular}{|c|c|c|c|c|}
\hline GRCC Section & Mesh Size & $\operatorname{Pn}(k N)$ & Maximum Glass Stress (MPa) & Estimated Cost (\$USD) \\
\hline $150 \times 150 \times 3 \times 25$ & 25 & 968.4 & 81.4 & $\$ 30.15$ \\
\hline $150 \times 150 \times 3 \times 19$ & 25 & 865.1 & 91.1 & $\$ 24.93$ \\
\hline $150 \times 150 \times 3 \times 12.5$ & 25 & 733.5 & 111.6 & $\$ 18.57$ \\
\hline $150 \times 150 \times 3 \times 9.5$ & 25 & 590.0 & 115.4 & $\$ 15.38$ \\
\hline $150 \times 150 \times 3 \times 6$ & 25 & 304.3 & 91.9 & $\$ 11.46$ \\
\hline $150 \times 150 \times 3 \times 3$ & 25 & 81.7 & 48.3 & $\$ 7.94$ \\
\hline $125 \times 125 \times 3 \times 25$ & 25 & 492.6 & 52.4 & $\$ 23.99$ \\
\hline $125 \times 125 \times 3 \times 19$ & 25 & 486.9 & 64.1 & $\$ 20.07$ \\
\hline $125 \times 125 \times 3 \times 12.5$ & 25 & 425.3 & 79.9 & $\$ 15.12$ \\
\hline $125 \times 125 \times 3 \times 9.5$ & 25 & 363.8 & 87.4 & $\$ 12.59$ \\
\hline $125 \times 125 \times 3 \times 6$ & 25 & 230.4 & 84.9 & $\$ 9.43$ \\
\hline $125 \times 125 \times 3 \times 3$ & 25 & 84.3 & 60.6 & $\$ 6.56$ \\
\hline $100 \times 100 \times 3 \times 25$ & 25 & 213.9 & 31.0 & $\$ 17.83$ \\
\hline $100 \times 100 \times 3 \times 19$ & 25 & 214.2 & 37.6 & $\$ 15.21$ \\
\hline $100 \times 100 \times 3 \times 12.5$ & 25 & 196.7 & 48.3 & $\$ 11.68$ \\
\hline $100 \times 100 \times 3 \times 9.5$ & 25 & 171.0 & 53.3 & $\$ 9.80$ \\
\hline $100 \times 100 \times 3 \times 6$ & 25 & 123.7 & 58.6 & $\$ 7.41$ \\
\hline $100 \times 100 \times 3 \times 3$ & 25 & 75.5 & 69.1 & $\$ 5.19$ \\
\hline $90 \times 90 \times 3 \times 25$ & 25 & 133.3 & 22.6 & $\$ 15.36$ \\
\hline $90 \times 90 \times 3 \times 19$ & 25 & 139.8 & 28.3 & $\$ 13.27$ \\
\hline $90 \times 90 \times 3 \times 12.5$ & 25 & 136.9 & 38.3 & $\$ 10.30$ \\
\hline $90 \times 90 \times 3 \times 9.5$ & 25 & 118.1 & 41.7 & $\$ 8.68$ \\
\hline $90 \times 90 \times 3 \times 6$ & 25 & 86.7 & 46.3 & $\$ 6.59$ \\
\hline $90 \times 90 \times 3 \times 3$ & 25 & 58.3 & 60.0 & $\$ 4.63$ \\
\hline $75 \times 75 \times 3 \times 25$ & 25 & 77.2 & 17.5 & $\$ 11.66$ \\
\hline $75 \times 75 \times 3 \times 19$ & 25 & 72.6 & 19.1 & $\$ 10.35$ \\
\hline $75 \times 75 \times 3 \times 12.5$ & 25 & 73.4 & 26.0 & $\$ 8.23$ \\
\hline $75 \times 75 \times 3 \times 9.5$ & 25 & 62.3 & 27.6 & $\$ 7.01$ \\
\hline $75 \times 75 \times 3 \times 6$ & 25 & 48.8 & 32.3 & $\$ 5.38$ \\
\hline $75 \times 75 \times 3 \times 3$ & 25 & 34.0 & 42.9 & $\$ 3.81$ \\
\hline $50 \times 50 \times 3 \times 19$ & 25 & 24.0 & 12.7 & $\$ 5.50$ \\
\hline $50 \times 50 \times 3 \times 12.5$ & 25 & 23.2 & 14.7 & $\$ 4.79$ \\
\hline $50 \times 50 \times 3 \times 9.5$ & 25 & 21.6 & 16.4 & $\$ 4.21$ \\
\hline $50 \times 50 \times 3 \times 6$ & 25 & 17.4 & 19.0 & $\$ 3.35$ \\
\hline $50 \times 50 \times 3 \times 3$ & 25 & 10.8 & 21.9 & $\$ 2.43$ \\
\hline
\end{tabular}

Next, the buckling loads vs. costs of the different dimensions of the GRCCs are graphically presented. This is shown in Figures 13 and 14. Due to the ranges of the values, two graphs are presented; Figure 13 covers the range of strengths from 1000 to $250 \mathrm{kN}$ while 14 covers 250 to $0 \mathrm{kN}$. 


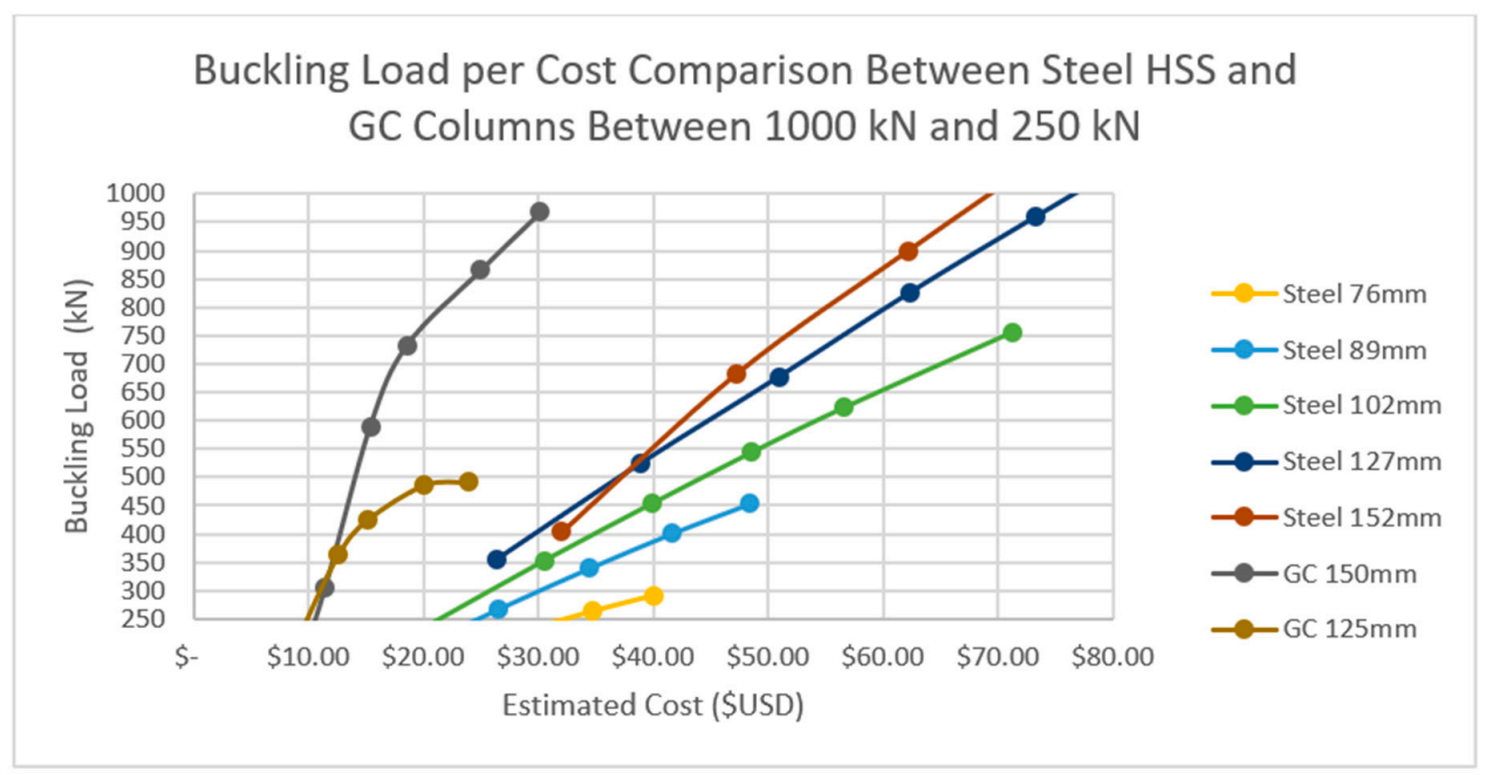

Figure 13. The cost vs. buckling load comparison between the hollow-structural-steel (HSS) sections and the GRCCs. This figure covers the buckling loads for 1000 to $250 \mathrm{kN}$.

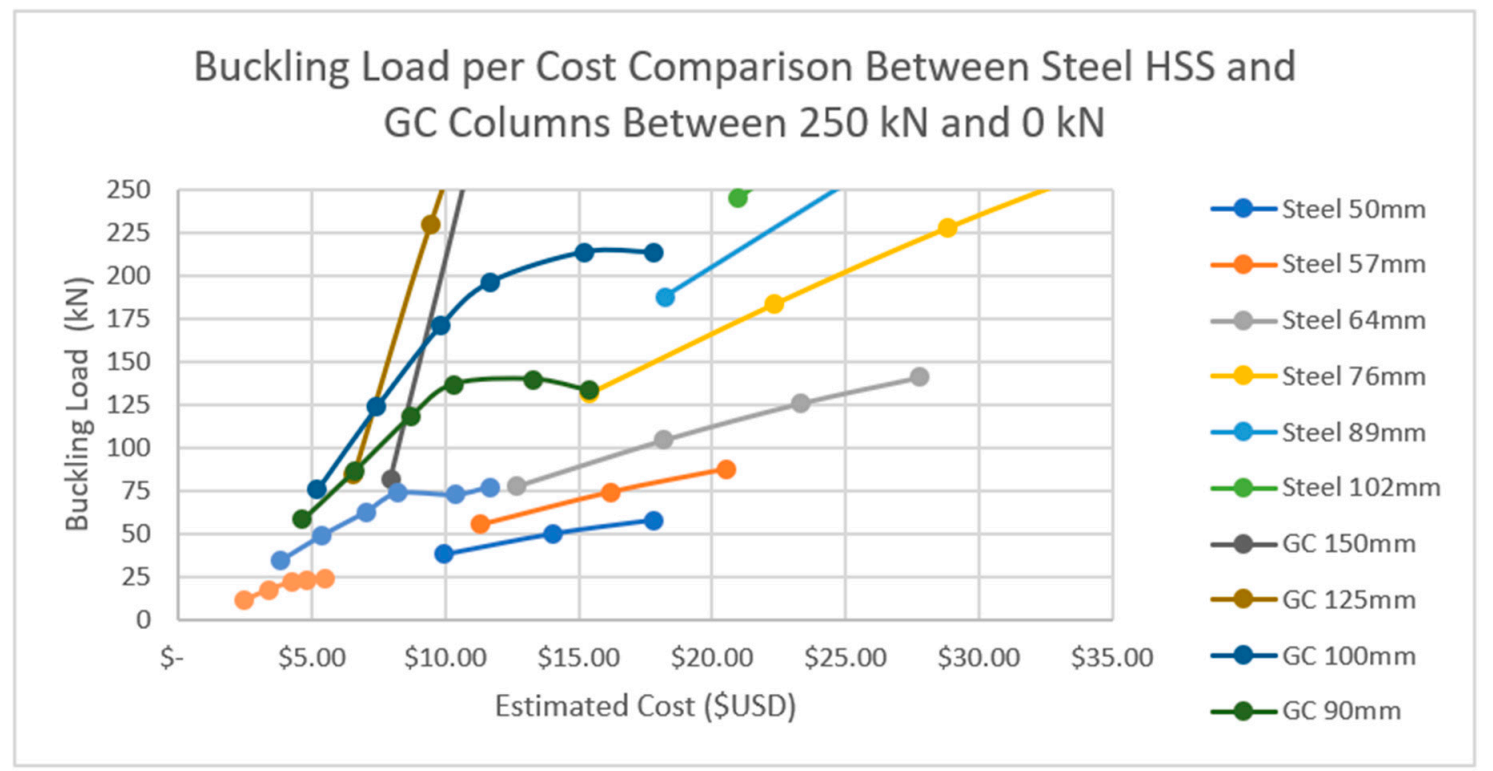

Figure 14. The cost vs. buckling load comparison between the hollow-structural-steel (HSS) sections and the GRCCs. This figure covers the buckling loads for 250 to $0 \mathrm{kN}$.

As can be seen in the graphs above, GRCCs tend to have lower costs, with cost savings up to $50 \%$ over their HSS equivalents. However, GRCCs tend to have lower buckling loads for equivalent outside dimensions, particularly for the smaller OD GRCCs. This means that if the dimensions of the column are restricted, it may require the use of a steel section.

\section{Interpretation of the Results}

Looking at the results, there are three primary regions that describe the buckling load to cost relationships between columns controlled by buckling failure. These regions can be seen in Figure 15 below. Figure 15 is the buckling load to cost curve of the GRCC $125 \mathrm{~mm} \times 125 \mathrm{~mm}$ for the different 
glass plate thicknesses. Specifically, Figure 15 highlights three primary regions for the curve, denoted $\mathrm{A}, \mathrm{B}$, and $\mathrm{C}$.

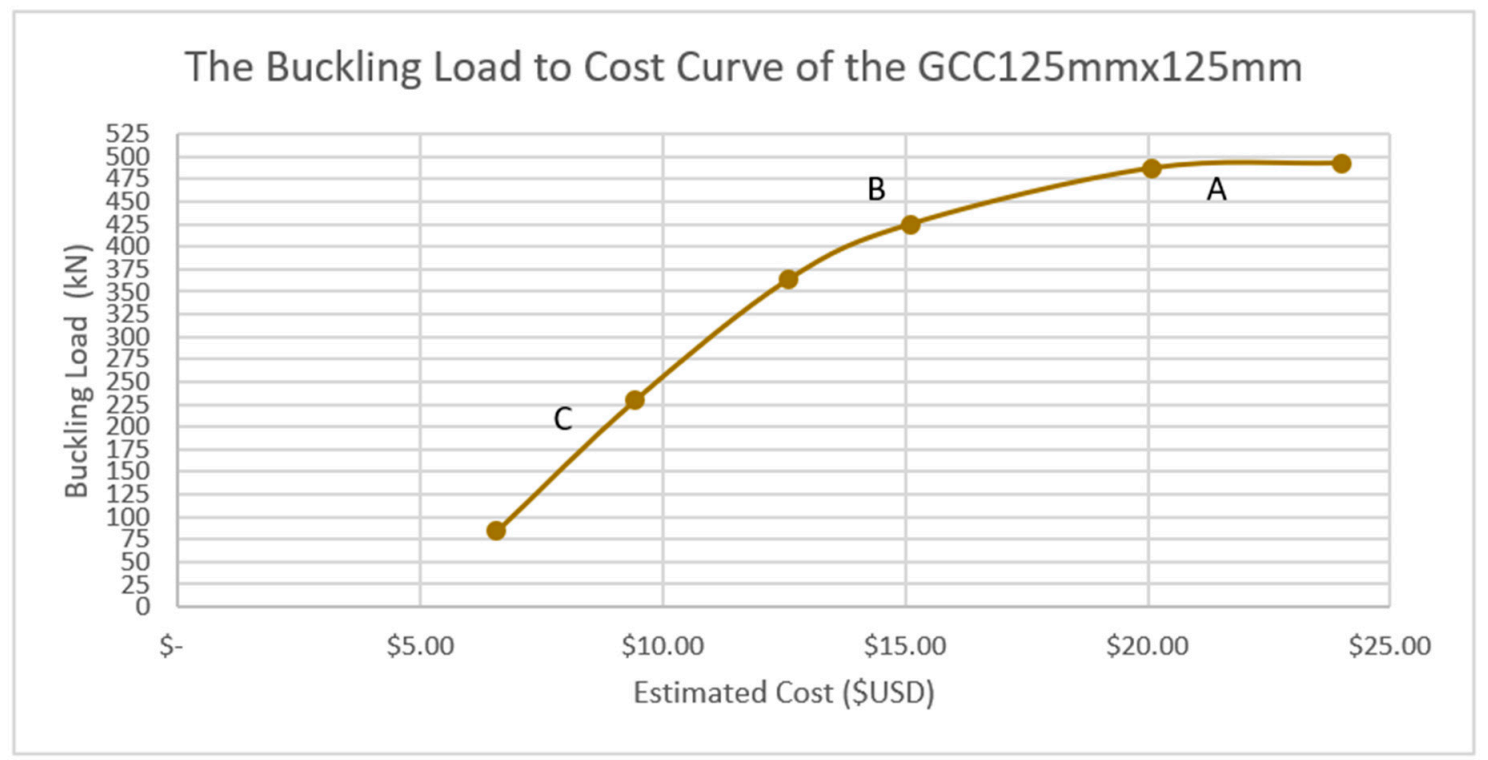

Figure 15. The buckling buckling load vs. cost graph for the GRCC $125 \times 125 \times 3$. The glass is varied to produce the cost curve. This figure highlights the regions A, B, and C, each having specific attributes.

These regions correspond to three conditions occurring in the GRCC. Region A is the location to which increasing glass content does not significantly add to the buckling load of the column. This occurs as the moment of inertia is not significantly improved by additional glass as the additional glass is placed closer to the centroid of the column.

Region B is the region in which most economical designs occur. HSS appears to all be within this region, indicating that the original design of HSS most likely took this into account. This region is the preferred region for GRCC as well as it produces the most buckling load for the cost. The failure modes expected are gross buckling of the column, as is seen in Figures 6 and 7.

Region $C$ occurs when the glass begins to locally buckle. This can be seen in Figure 16. In this figure, the HDPE sleeve is not able to prevent the glass from greatly displacing locally at the top of the column. This results in premature failure of the column, preventing it from being able to fully engage the section. As a result, the column begins to rapidly lose buckling load for the given cost, as is reflected in Figure 15's region C.

It should be mentioned that the deflected shape in Figure 16 appears as though it is debonding, but this occurs as the ANSYS program exaggerates the deflections of individual elements; these exaggerated deflections cause the localized overlap and stretched look at the top of the column in Figure 16. If desired, these excessive deflections can be depressed by utilizing large deflections within ANSYS. However, the authors have opted to utilize the exaggerated deflections to allow viewing of the buckling failure mode.

This condition of local buckling of shapes occurs in HSS. As Reference [28] indicated, there exists a region in which steel sections are considered slender. Specifically, the local buckling based on plate buckling is a similar condition, which is described in the commentary, section E7.2. Slender Stiffened Elements, $Q_{n}$ of Reference [28]. 


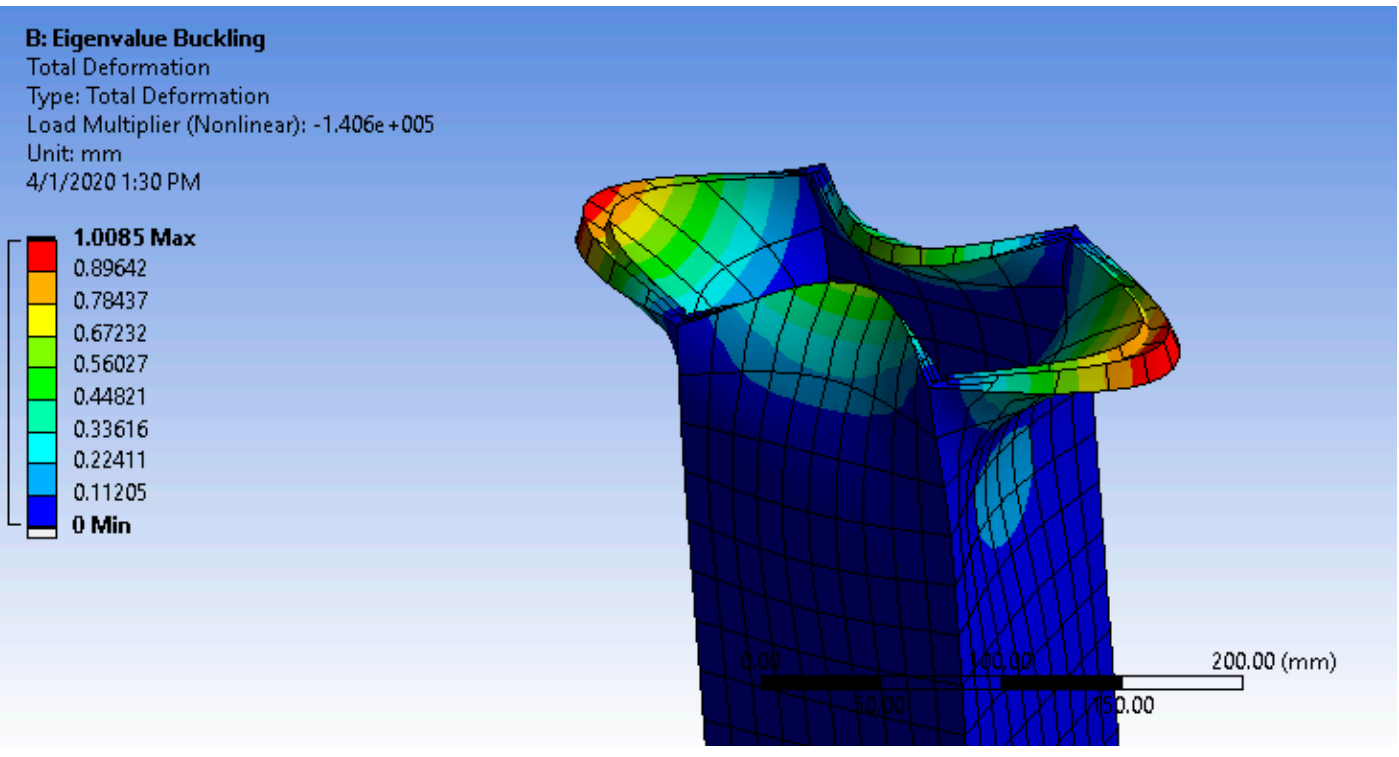

Figure 16. Local buckling of GRCCs occurs when the high-density polyethylene (HDPE) sleeve cannot provide sufficient stiffness to prevent the glass from locally buckling at the point of loading.

\section{Required Bond Strengths}

Much of this paper assumed that the bond strengths between the glass plates and polymer sleeves were sufficient to prevent delamination of the composites.

To make this determination, the shear stresses at the polymer-glass interface for the $2 \times 4$ stud equivalents were determined. For these sections, the shear stresses are shown in Figures 17 and 18. In Figure 17, the maximum shear stress is shown for the $89 \times 38 \times 3 \times 1$ GRCC at the weak-axis buckling loading of $4.43 \mathrm{kN}$.

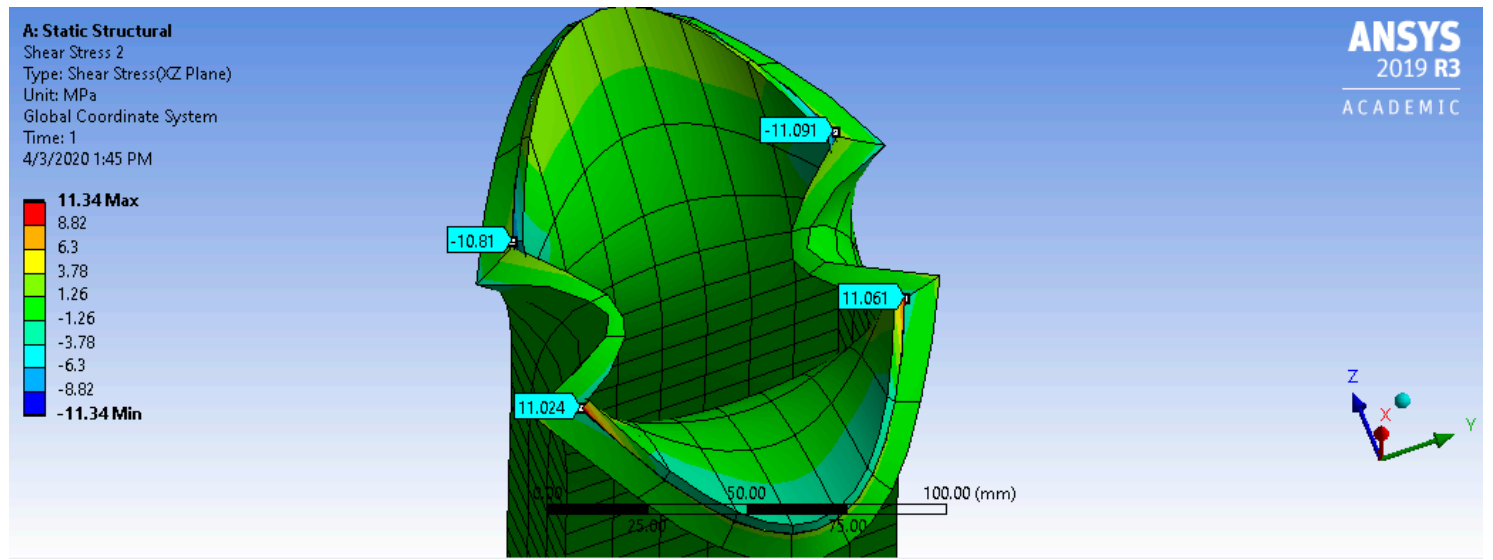

Figure 17. Shear stress at the interface between the glass sheets and HDPE for the $89 \times 38 \times 3 \times 1$ GRCC.

In Figure 18, the shear stresses at the interface is shown for the $89 \times 38 \times 3 \times 4$ GRCC. This column is also loaded to its weak-axis failure loading of $12.0 \mathrm{kN}$. Note that the stresses in Figure 18 are at most $1.7158 \mathrm{MPa}$, which is significantly smaller than the maximum shear stress of $11.091 \mathrm{MPa}$ indicated in Figure 17.

Similar to the previous two examples, a third (Figure 19) is shown; this is the $150 \times 150 \times 3 \times 3$ GRCC at the buckling load. Note that these stresses are less than the worst case from Figure 17 above. 


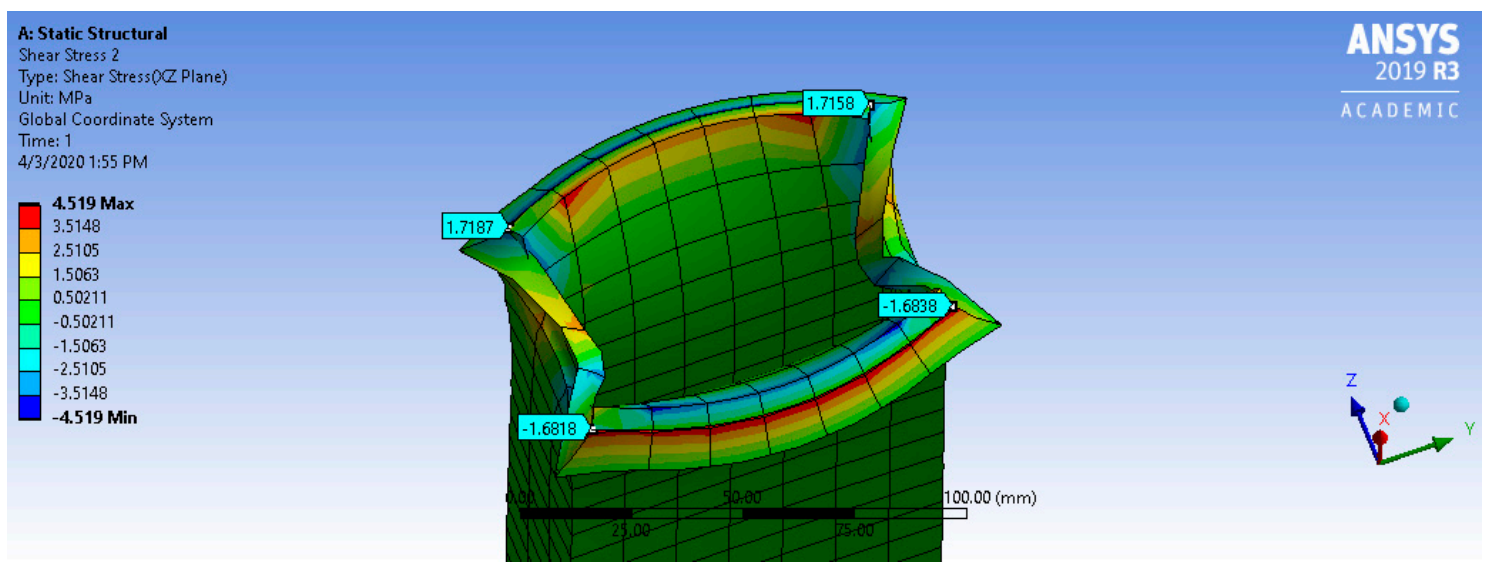

Figure 18. Shear stress at the interface between the glass sheets and HDPE for the $89 \times 38 \times 3 \times 4$ GRCC.

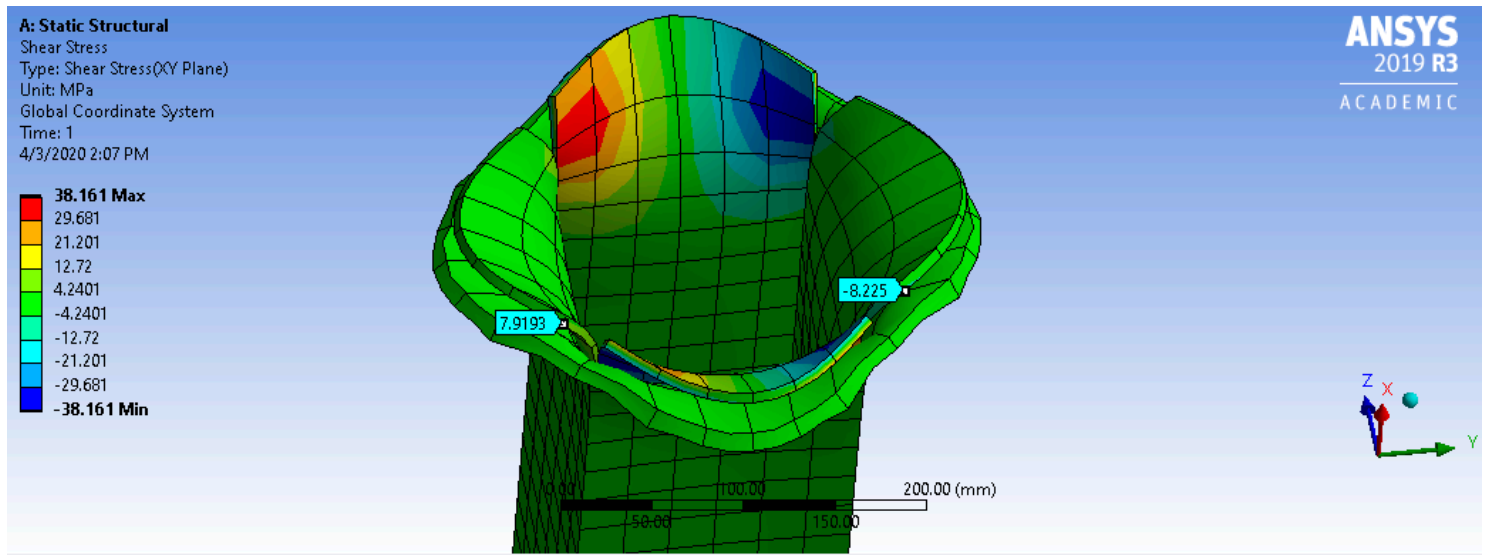

Figure 19. Shear stress at the interface between the glass sheets and HDPE for the $150 \times 150 \times 3 \times 3$.

So, the worst-case design is that of the $89 \times 38 \times 3 \times 1$, which if loaded in the strong axis, the shear stress would become $30.69 \mathrm{MPa}$ (as the ratio between the weak and strong axis buckling loads is 2.77:1).

These stresses are within the acceptable limits for typical sizing agents. For instance, Reference [29] indicated that interfacial shear stresses up to $44 \mathrm{MPa}$ are possible, with $32 \mathrm{MPa}$ being the lower limit of their samples.

\section{Conclusions}

Glass-reinforced composite columns (GRCCs) were investigated from a cost standpoint, to determine if GRCCs could be constructed at a cost that lower than competing structural materials. GRCCs, when constructed to compete against No. 3 grade Douglas fir, can provide comparable buckling loads while costing $11 \%$ less than the equivalent timber. Additionally, it was found that GRCCs can provide up to $50 \%$ cost savings over equivalent steel columns, although GRCCs tend to have lower buckling loads for their overall dimensions. This means in applications where size limitations are stringent, steel will likely be three superior choice, but this is dependent on a number of factors.

These cost estimates were based on an assumed factor of $40 \%$ for the manufacturing costs for the intended to be over jacketing extruded sections [25]. This assumption may be inaccurate, al though no cost estimation alternative has been found. Additionally, this paper assumed that appropriate bond strengths could be developed between the glass plates and the polymers, a requirement for bonding the glass to the exterior sleeve of polymer. This is possible using sizing agents, chemicals 
utilized by the glass-fibers industry, although the costs are not reflected in the estimated costs presented. While specific sizing agent interfacial shear stresses for HDPE have not been researched, the interfacial shear stresses of similar use (for epoxies) have strengths that are within the stresses presented in this paper.

The paper concluded with remarks about how increasing glass reinforcement aids in increasing the buckling loads of the GRCCs, but only to a point. Also, a condition of local buckling failure in which the polymers were unsuccessful in securing the glass plates was found when glass thicknesses decreased excessively.

Author Contributions: Conceptualization, J.C., R.G.; methodology, J.C.; software, J.C.; formal analysis, J.C.; investigation, J.C., R.G.; writing — original draft preparation, J.C.; writing - review and editing, R.G.; supervision, R.G.; project administration, R.G.; funding acquisition, R.G. All authors have read and agreed to the published version of the manuscript.

Funding: This research received no external funding.

Conflicts of Interest: The authors declare no conflict of interest.

\section{Appendix A}

The calculations regarding the GRCC $89 \times 38 \times 1.6 \times 3$ are shown below.

$$
\begin{array}{r}
I_{\text {weak axis }}(\text { glass component })=\bar{y}^{2} A=2(12.2 \mathrm{~mm})^{2}(77 \mathrm{~mm} \times 1.6 \mathrm{~mm})=36,674 \mathrm{~mm}^{4} \\
I_{\text {weak axis }}\left(\mathrm{HDPE} \quad \begin{array}{r}
\text { sleeve })=\frac{1}{12}\left(b_{o} \mathrm{~h}_{o}^{3}-b_{i} \mathrm{~h}_{i}^{3}\right) \\
=\frac{1}{12}\left[89 \mathrm{~mm}(38 \mathrm{~mm})^{3}-77 \mathrm{~mm}(26 \mathrm{~mm})^{3}\right] \\
=294,188 \mathrm{~mm}^{4}
\end{array}\right. \\
\begin{array}{r}
I_{\text {strong axis }}(\text { glass component })=\frac{1}{12} b h^{3}=\frac{1}{12}(2 \times 1.6 \mathrm{~mm})(77 \mathrm{~mm})^{3}=121,742 \mathrm{~mm}^{4} \\
\text { sleeve })=\frac{1}{12}\left(b_{o} \mathrm{~h}_{o}^{3}-b_{i} \mathrm{~h}_{i}^{3}\right)
\end{array} \\
I_{\text {strong axis }}\left(H D P E \quad=\frac{1}{12}\left[38 \mathrm{~mm}(89 \mathrm{~mm})^{3}-26 \mathrm{~mm}(77 \mathrm{~mm})^{3}\right]=1,243,247 \mathrm{~mm}^{4}\right.
\end{array}
$$

where $I$ is the moment of inertia, denoted for each axis. Accordingly, the critical buckling load for each axis is calculated using the Euler's critical load formula (which was originally developed by Leonhard Euler in 1757, though [30] provides an explanation):

$$
\begin{gathered}
F_{c r}=\frac{\pi^{2} E I}{(k L)^{2}} \\
F_{c r, \text { weak axis }}=\frac{\pi^{2}(72 \mathrm{GPa})\left(36,674 \mathrm{~mm}^{4}\right)}{(2440 \mathrm{~mm})^{2}}+\frac{\pi^{2}(0.8 \mathrm{GPa})\left(294,188 \mathrm{~mm}^{4}\right)}{(2440 \mathrm{~mm})^{2}}=4,768 \mathrm{~N} \\
F_{c r \text {, strong axis }}=\frac{\pi^{2}(72 \mathrm{GPa})\left(121,742 \mathrm{~mm}^{4}\right)}{(2440 \mathrm{~mm})^{2}}+\frac{\pi^{2}(0.8 \mathrm{GPa})\left(1,243,247 \mathrm{~mm}^{4}\right)}{(2440 \mathrm{~mm})^{2}}=16,163 \mathrm{~N}
\end{gathered}
$$

where $E$ is the Young's modulus of glass, $k$ is the length correction factor, and $L$ is the length of the column.

The calculations regarding the GRCC $125 \times 125 \times 3 \times 12.5$ are shown below.

First, the buckling resistance is determined by the moment of inertia. This is calculated accordingly:

$$
\begin{gathered}
I=\frac{2}{12}(12.5 \mathrm{~mm}) \quad(94 \mathrm{~mm})^{3}+\frac{2}{12}(94 \mathrm{~mm})(12.5 \mathrm{~mm})^{3}+2(53.25 \mathrm{~mm})^{2}(94 \mathrm{~mm} \times 12.5 \mathrm{~mm}) \\
=8,761,142 \mathrm{~mm}^{4}
\end{gathered}
$$


Next, the critical load is calculated according to Equation (A3):

$$
F_{c r}=\frac{\pi^{2}(72 \mathrm{GPa})\left(8,761,142 \mathrm{~mm}^{4}\right)}{(3050 \mathrm{~mm})^{2}}=669 \mathrm{kN}
$$

\section{References}

1. Cotter, J.; Guldiken, R. Theoretical Design Strategies, Strengths, Costs, and Environmental Impacts of Triple Composite Beams Utilizing Glass Compressive Reinforcement. J. Compos. Sci. 2020, 4, 22. [CrossRef]

2. Bos, F.; Louter, P. Challenging Glass: Conference on Architectural and Structural Applications of Glass; Faculty of Architecture, Delft University of Technology: Delft, The Netherlands, 2008.

3. Northolt, M. Compressive strength and glass transition temperature. J. Mater. Sci. 1981, 16, 2025-2028. [CrossRef]

4. Zhan, Y.; Wu, G. Global buckling capacity of pultruded FRP-I section columns under axial compression. Mech. Res. Commun. 2018, 90, 8-17. [CrossRef]

5. Wong, P.; Wang, Y. An experimental study of pultruded glass fibre reinforced plastics channel columns at elevated temperatures. Compos. Struct. 2007, 81, 84-95. [CrossRef]

6. Correia, M.; Nunes, F.; Correia, J.; Silvestre, N. Buckling behavior and failure of hybrid fiber-reinforced polymer pultruded short columns. J. Compos. Constr. 2013, 17, 463-475. [CrossRef]

7. Nunes, F.; Correia, J.R.; Silvestre, N. Structural behaviour of hybrid FRP pultruded columns. Part 1: Experimental study. Compos. Struct. 2016, 139, 291-303. [CrossRef]

8. Nunes, F.; Silvestre, N.; Correia, J.R. Structural behaviour of hybrid FRP pultruded columns. Part 2: Numerical study. Compos. Struct. 2016, 139, 304-319. [CrossRef]

9. Ivashchenko, E. Sizing and finishing agents for basalt and glass fibers. Theor. Found. Chem. Eng. 2009, 43, 511-516. [CrossRef]

10. Tang, L.G.; Kardos, J.L. A review of methods for improving the interfacial adhesion between carbon fiber and polymer matrix. Polym. Compos. 1997, 18, 100-113. [CrossRef]

11. MIichelman, Michem®Emulsion 93135M. Available online: https://www.michelman.com/Michem-Emulsion/ Michem(r)-Emulsion-93135M/ (accessed on 3 April 2020).

12. Cardoso, D.C.; Harries, K.A.; Batista, E.D.M. Compressive strength equation for GFRP square tube columns. Compos. Part B Eng. 2014, 59, 1-11. [CrossRef]

13. Kalpakjian, S. Manufacturing Processes for Engineering Materials, 6th ed.; Pearson Education Inc.: Hoboken, NJ, USA, 2017.

14. Vanevenhoven, L.M.; Shield, C.K.; Bank, L.C. LRFD factors for pultruded wide-flange columns. J. Struct. Eng. 2010, 136, 554-564. [CrossRef]

15. Hunt, D.P. Combination Metal and Composite Stud. U.S. Patent 5,713,176, 3 February 1998.

16. Forest2Market. North American Lumber Market: Adjusting to Uncertainty. Forest2Market Blog. 2020. Available online: https://www.forest2market.com/blog/north-american-lumber-market-adjusting-touncertainty (accessed on 31 March 2020).

17. Forest2Market. North American Softwood Lumber Prices Steady Despite Market Uncertainty. Forest2Market Blog. 2019. Available online: https://www.forest2market.com/blog/north-american-softwood-lumber-pricessteady-despite-market-uncertainty (accessed on 31 March 2020).

18. Ochshorn, J. Capacity of Wood Column Calculator. Cornell.edu. 2014. Available online: https://courses.cit. cornell.edu/arch264/calculators/example7.1/index.html (accessed on 31 March 2020).

19. Council, A.W. National Design Specification (NDS) for Wood Construction, 2012nd ed.; American Wood Council Leesburg: Leesburg, VA, USA, 2012.

20. Council, A.W. National Design Specification (NDS) for Wood Construction, 2005th ed.; American Wood Council Leesburg: Leesburg, VA, USA, 2005.

21. AbrisaTechnologies. Specialty Glass Products Technical Reference Document Soda-Lime Float Glass. Available online: https://abrisatechnologies.com/specs/Soda-Lime\%20Float\%20Glass\%20Spec\%20Sheet $\%$ 2012_10.pdf (accessed on 25 March 2020).

22. ToolBox, E. Young's Modulus-Tensile and Yield Strength for common Materials. 2003. Available online: https:/www.engineeringtoolbox.com/young-modulus-d_417.html (accessed on 21 November 2019). 
23. Alibaba.com. Available online: https://www.alibaba.com/products/soda_lime_glass_sheet.html?IndexArea= product_en\&sort_type=TRALV (accessed on 21 November 2019).

24. Alibaba.com. Available online: https://www.alibaba.com/trade/search?fsb=y\&IndexArea=product_en\& CatId=\&SearchText=high +density+polyethylene (accessed on 21 November 2019).

25. Griff, A. The Real Economics of Extrusion. Plastics Today. 2018. Available online: https://www.plasticstoday. com/extrusion-pipe-profile/real-economics-extrusion/190306234159293 (accessed on 25 March 2020).

26. MetalMiner. Carbon Steel MetalMiner Prices. 2020. Available online: https://agmetalminer.com/metalprices/carbon-steel/ (accessed on 1 April 2020).

27. EngineersEdge. Coefficient of Friction Equation and Table Chart. 2020. Available online: www.engineersedge. com (accessed on 24 March 2020).

28. AISC. Steel Construction Manual, 13th ed.; American Institute of Steel Construction: Chicago, IL, USA, 2005; pp. 16.1-268-16.1-272.

29. Hiasa, T.; Kobayashi, D.; Ichikawa, T.; Endo, M. Sizing Agent-coated Reinforcing Fibers, Method for Producing Sizing Agent-coated Reinforcing Fibers, Prepreg, and Fiber-reinforced Composite Material. U.S. Patent 10,208,173, 19 February 2019.

30. Hibbeler, R.C. Mechanics of Materials, 8th ed.; Pearson Prentice Hall: Upper Saddle River, NJ, USA, 2008; pp. 693-704.

(C) 2020 by the authors. Licensee MDPI, Basel, Switzerland. This article is an open access article distributed under the terms and conditions of the Creative Commons Attribution (CC BY) license (http://creativecommons.org/licenses/by/4.0/). 